\title{
Changes in adenylyl cyclase activity in human endometrium during the menstrual cycle and in human decidua during pregnancy
}

\author{
N. Tanaka, K. Miyazaki*, H. Tashiro, H. Mizutani and H. Okamura \\ Department of Obstetrics and Gynaecology, Kumamoto University School of Medicine, 1-1-1 Honjo, \\ Kumamoto 860, Japan
}

\begin{abstract}
Adenylyl cyclase activity was studied in human endometrium during the menstrual cycle and in human decidua during pregnancy. Higher adenylyl cyclase activity was found in the endometrium than in the myometrium, corpus luteum or Fallopian tubes. In the endometrium, the basal and stimulated activities were highest in the fundus and decreased slightly from the fundus to the isthmus. Prostaglandin-stimulated adenylyl cyclase activity increased gradually from the proliferative phase to the secretory phase, and then quickly reached its highest value in the late secretory phase. Catecholamine-stimulated adenylyl cyclase activity reached a peak in the late proliferative phase and decreased significantly thereafter. Forskolinstimulated activity was significantly higher throughout the secretory phase than in the proliferative phase. In the decidua, prostaglandin-, catecholamine- and forskolin-stimulated adenylyl cyclase activities in late pregnancy were significantly lower than those in early pregnancy. Our results demonstrate dramatic alterations in adenylyl cyclase activity in human endometrium during the menstrual cycle and in human decidua during pregnancy.
\end{abstract}

\section{Introduction}

The human endometrium, a typical target tissue of ovarian steroid hormones, is regulated by oestrogen and progesterone, and undergoes a cycle of proliferation, differentiation and desquamation. Under the influence of these hormones and in the presence of the trophoblast, the endometrium is transferred into the decidua. The function of the decidua has not been clearly defined but suggested functions include a role in the implantation and nutrition of the blastocyst and in the immunological separation of maternal and fetal tissues.

Cyclic nucleotides that may have various physiological roles are present in the endometrium and the decidua, and are modulated by steroid hormones in the human endometrium (Bergamini et al., 1985), human decidua (Whitsett and Johnson, 1979), rabbit endometrium and decidua (Bekairi et al., 1984; Fortier et al., 1987, 1990) and other tissues. We have reported that multiple protein kinases, particularly types I and II cAMPdependent protein kinases, are regulated by oestrogen and progesterone in human and rabbit endometria via de novo synthesis (Miyazaki et al., 1980a,b). Furthermore, it has been demonstrated that phosphorylation mediated by cyclic nucleotides may be involved in the regulation of steroid hormone receptor binding (Fleming et al., 1983), the control of intracellular free calcium (Reuter, 1983) and sodium (Costa et al., 1982) concentrations. Significant quantities of prostaglandins (PGs) (Singh et al., 1975) and catecholamines (Dujovne et al., 1976) are present and cause alterations in the human uterus during the menstrual cycle. These reports suggest that the human endometrium

${ }^{*}$ Corresponding author.

Received 25 March 1992 may be regulated not only by steroid hormones but also by catecholamines and PGs that affect adenylyl cyclase activity.

The pharmacological features of endometrial adenylyl cyclase activity have been investigated by several researchers using bovine (Bhalla et al., 1972), rat (Vesin et al., 1978) and human (Bergamini et al., 1985) endometria. Bergamini et al. (1985) demonstrated that endometrial adenylyl cyclase activity was stimulated by sodium fluoride and $5^{\prime}$ guanylyl imidodiphosphate $(\mathrm{Gpp}(\mathrm{NH}) \mathrm{p})$, and that treatment of secretory endometrial membranes in vitro with oestradiol stimulates adenylyl cyclase activity, compared with the adenylyl cyclase activity of proliferative endometrial membranes. Houserman et al. (1989) reported that progesterone enhanced the effect of PG- and forskolinstimulated adenylyl cyclase activities in oestrogen-primed endometrial stromal cells in vitro. However, there have been no reports about alterations in adenylyl cyclase activity in human endometrium during the menstrual cycle and in human decidua during pregnancy.

The smooth muscle of the Fallopian tube is innervated by adrenergic nerve fibres along its entire length (Brundin and Wirsen, 1964). The theca externa of the Graafian follicle contains numerous cholinergic nerves (Stefenson et al., 1981), and adrenergic nerve terminals are seen in the wall of the whole Graafian follicle (Owman et al., 1975). Catecholamines are thought to play an important role in the ovary (Weiss et al., 1982; Wheeler et al., 1987) and in the Fallopian tube (Dujovne et al., 1976).

$\mathrm{PGF}_{2 \alpha}$ may have a role in luteolysis. $\mathrm{PGF}_{2 \alpha}$ is produced by human corpora lutea and specific receptors for $\mathrm{PGF}_{2 \alpha}$ are present in human luteal tissue (Powell et al., 1974). PGs evoke myometrial contractions in women (Karim et al., 1968), and regulate oviduct motility (Spilman, 1974). We therefore 
examined PG- and catecholamine-stimulated adenylyl cyclase activity in the myometrium, corpus luteum and Fallopian tube. We studied alterations in PG-, catecholamine-, NaF- and forskolin-stimulated adenylyl cyclase activities in human endometrium during the menstrual cycle and in human decidua during pregnancy.

\section{Materials and Methods}

\section{Chemicals}

$\left[2,8-{ }^{3} \mathrm{H}\right] \mathrm{cAMP}\left(30-34 \mathrm{Ci} \mathrm{mmol}^{-1}\right)$ was obtained from New England Nuclear (Boston, MA); L-isoproterenol, L-adrenaline, L-noradrenaline, $\mathrm{PGE}_{2}, \mathrm{PGF}_{2 \alpha^{\prime}} \mathrm{NaF}, \mathrm{cAMP}, \mathrm{ATP}$ and GTP were from Sigma Chemical Co. (St Louis, MO); RPMI 1640 medium was from GIBCO Laboratories (Grand Island, NY). Forskolin was kindly provided by Hoechst A.G. (Frankfurt, Germany) through Nippon Kayaku Co. Ltd. Other chemicals were of analytical grade.

\section{Tissue collection and preparation}

Tissue samples from 61 endometria, four myometria, four corpora lutea and four Fallopian tubes were obtained, after written consent, from premenopausal patients with uterine myoma, carcinoma in situ or microinvasive carcinoma of the cervix, or early stage ovarian carcinoma. All of these patients had a history of regular menstrual cycles and no endocrine disorders. Decidual tissues in early pregnancy (gestational ages 5-10 weeks) were obtained from six women, whose pregnancy had been terminated by dilatation and curettage. Decidual tissues in late pregnancy (gestational ages $37-40$ weeks) were obtained from five term pregnancies in which Caesarean sections had been performed. Written consent of these patients was obtained. The patients were between 27 and 46 years old. Immediately after collection, samples were transported to the laboratory in RPMI 1640 medium at $37^{\circ} \mathrm{C}$. After removal of blood clots and mucus, tissue samples were excised. Endometrial and luteal tissue (20-60 mg wet weight) were homogenized with 30 volumes of a homogenizing solution containing 2 mmol Tris- $\mathrm{HCl} \mathrm{l}^{-1}$ (pH 7.4) and $2 \mathrm{mmol} \mathrm{EGTA} \mathrm{l}^{-}$ ${ }^{1}$, in a glass homogenizer on ice. Myometrial and tubal tissues (150-250 mg wet weight) were homogenized with three $10 \mathrm{~s}$ bursts at a setting of 5 in a Polytoron (Kinematica, Steinhofhald, Switzerland) in 10 volumes of the same homogenizing solution and were subsequently homogenized in a glass homogenizer on ice.

A part of each tissue sample obtained was reserved for histological examination and these samples were dated by the method of Noyes et al. (1950). The normal endometrial tissue was classified into five groups: early proliferative (day 1-10), late proliferative (day 11-15), early secretory (day 16-19), mid-secretory (day 20-23) and late secretory phase (day 24-28).

\section{Determination of adenylyl cyclase activity}

The assay was performed within $1 \mathrm{~h}$ of removal of the uterus, without freezing the tissue and without separating the endometrium into epithelial and stromal cells, as freezing the tissue and cell digestion resulted in a decrease in the basal and stimulated adenylyl cyclase activities. Adenylyl cyclase activity was measured according to Miyazaki ef al. (1984), in an assay system containing in a final volume of $60 \mu \mathrm{l}, 80 \mathrm{mmol}$ Tris- $\mathrm{HCl}$ $1^{-1}$ (pH 7.4), $1 \mathrm{mmol} \mathrm{MgSO} \mathrm{l}^{-1}, 0.8 \mathrm{mmol} \mathrm{EGTA}^{-1}, 10 \mathrm{mmol}$

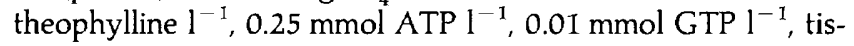
sue homogenate $(30-40 \mu \mathrm{g}$ of protein) and the catecholamines, PGs or forskolin at the final concentrations indicated. PGs and forskolin were initially dissolved in absolute ethanol to achieve a concentration of $10 \mathrm{mmol}^{-1}$, and subsequent solutions were prepared using water as solvent. Basal activity was determined in the presence of an equal amount of ethanol. Results were expressed in picomoles of cAMP generated per $\mathrm{mg}$ of protein per minute. After incubation for $10 \mathrm{~min}$ at $30^{\circ} \mathrm{C}$ the reaction was terminated by placing each tube in boiling water for $2 \mathrm{~min}$.

The amount of cAMP produced was determined by the method of Brown et al. (1971), with some modification of the protein binding assay. The binding reagent was prepared from bovine adrenal extracts. The sensitivity of this assay was 0.1 to 40 pmoles per tube. Quadruplicate assays of adenylyl cyclase activity were made for each value determined.

\section{Protein assay}

The amount of protein was determined by the method of Lowry et al. (1951) using bovine serum albumin as a standard.

\section{Statistical analysis}

Data are expressed as means \pm SEM. Statistical comparisons were performed using analysis of variance and Scheffe's test.

\section{Results}

Basal and stimulated adenylyl cyclase activities were found to be proportional to the protein concentration in the tissue homogenate $(10-200 \mu \mathrm{g})$ and to the time $(0-25 \mathrm{~min})$ at $30^{\circ} \mathrm{C}$. Optimal conditions for measuring stimulated adenylyl cyclase activity were compared during different phases of the menstrual cycle. Maximal stimulation of endometrial adenylyl cyclase activity during the menstrual cycle was observed at concentrations of approximately $30 \mu \mathrm{mol} \mathrm{l}^{-1}$ for $\mathrm{PGE}_{2}$ and $\mathrm{PGF}_{2 \alpha}$ (Fig. 1a,b); $100 \mu \mathrm{mol}^{-1}$ for forskolin (Fig. 1c); $30 \mu \mathrm{mol}^{-1}$ for catecholamines (Fig. 1d) and $10 \mathrm{mmol} \mathrm{l}^{-1}$ for $\mathrm{NaF}$ (data not shown). For all subsequent assays, these concentrations were used.

The adenylyl cyclase activity in the endometrium was compared with that in other tissues from the late secretory phase of the menstrual cycle (Table 1). Human endometrium exhibited high basal adenylyl cyclase activity. Stimulation with PG or forskolin resulted in higher activities of adenylyl cyclase in the endometrium than in the myometrium, corpus luteum or Fallopian tube. When stimulated by catecholamines adenylyl cyclase activity was higher in the Fallopian tube than in the endometrium, myometrium or corpus luteum.

To evaluate whether there were regional differences in endometrial adenylyl cyclase activity, endometrial samples from different uterine areas of three patients were studied. Basal 

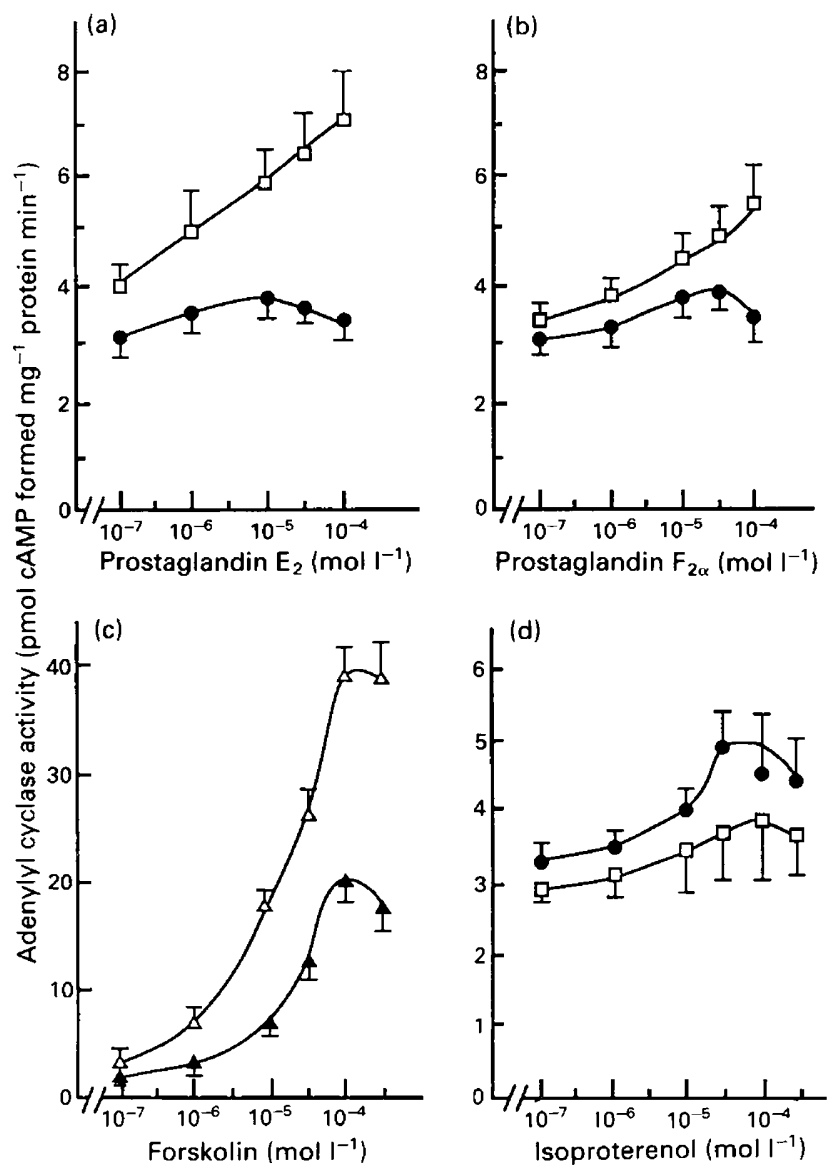

Fig. 1. Dose-response curves for stimulation of adenylyl cyclase activity by (a) prostaglandin $\mathrm{E}_{2^{\prime}}$ (b) prostaglandin $\mathrm{F}_{2 a^{\prime}}$ (c) forskolin and (d) isoproterenol during the human menstrual cycle. Endometrial tissues were obtained in the early proliferative $(\boldsymbol{\Delta})$, late proliferative $(O)$, early secretory $(\triangle)$ and late secretory $(\square)$ phases of the menstrual cycle. Quadruplicate assays of adenylyl cyclase activity were performed for each value determined. Data represent means \pm SEM of the results obtained from 3-4 different endometria.

and stimulated activities were highest in the fundus and decreased slightly, but not significantly, from the fundus to the isthmus. Thus, for all subsequent assays, endometrium from the fundal segment was used.

Immediately after homogenizing the tissue samples, cAMP content of the endometrium was measured. cAMP content varied widely among the tissue samples and there were no significant changes in CAMP content of the samples during the menstrual cycle or pregnancy. Basal activity of adenylyl cyclase also did not change significantly during the menstrual cycle or pregnancy.

$\mathrm{PGE}_{2^{-}}$and $\mathrm{PGF}_{2 \alpha^{-}}$-stimulated adenylyl cyclase activities increased gradually from the proliferative phase to the secretory phase of the menstrual cycle, and then quickly reached maximum values in the late secretory phase. $\mathrm{PGE}_{2}$-stimulated adenylyl cyclase activity was significantly higher $(P<0.05)$ in the late secretory phase than in the early proliferative, late proliferative and early secretory phases. $\mathrm{PGF}_{2 a}$-stimulated adenylyl cyclase activity was significantly higher in the late secretory phase $(P<0.01)$ than in the early proliferative phase. The effect of $\mathrm{PGE}_{2}$ on adenylyl cyclase activity was found to be greater than that of $\mathrm{PGF}_{2 \alpha}$ (Fig. 2).

Forskolin-stimulated adenylyl cyclase activity (Fig. 3a) rapidly increased after ovulation, reached a peak during the early secretory phase and maintained this value up to the late secretory phase. Forskolin-stimulated adenylyl cyclase activity in the early, mid- and late secretory phases was significantly higher $(P<0.01)$ than in the early proliferative phase. Forskolin appeared to be the most potent activator of adenylyl cyclase activity among the agents tested. In contrast, $\mathrm{NaF}$ stimulated activity decreased slightly, but not significantly, from the proliferative phase to the secretory phase of the menstrual cycle (Fig. 3b).

Isoproterenol- and adrenaline-stimulated activities were highest in the late proliferative phase and significantly decreased thereafter. Isoproterenol-stimulated adenylyl cyclase activity was significantly higher $(P<0.01)$ during the late proliferative and the early secretory phases than in the late secretory phase (Fig. 4a). Adrenaline-stimulated adenylyl cyclase activity was significantly higher $(P<0.05)$ during the late proliferative phase than in the late secretory phase. Noradrenaline, however, produced almost no alteration in adenylyl cyclase activity throughout the menstrual cycle (data not shown).

The changes in the sensitivity of the dose-response curve during the menstrual cycle were investigated by comparing the concentration giving the half-maximal response $\left(\mathrm{EC}_{50}\right)$ for each of the agents used in this study during the most sensitive and insensitive phases of the menstrual cycle. Each agent stimulated endometrial activity in a dose-dependent manner and maximum stimulation was seen at concentrations of $10-100 \mu \mathrm{mol} \mathrm{l}^{-1}$ for $\mathrm{PGE}_{2}$ and $\mathrm{PGF}_{2 \alpha}$ (Fig. 1a,b), 30-100 $\mu \mathrm{mol} \mathrm{l}^{-1}$ for catecholamines (Fig. 1d), $100 \mu \mathrm{mol} \mathrm{I}^{-1}$ for forskolin (Fig. 1c) and 10-20 mmol l-1 for $\mathrm{NaF}$ (data not shown). The apparent $\mathrm{EC}_{50}$ values were calculated from each dose-response curve. There were no significant changes in the $\mathrm{EC}_{50}$ values of $\mathrm{PGs}$ and catecholamines during the menstrual cycle. However, the $\mathrm{EC}_{50}$ values of forskolin showed significant differences during the menstrual cycle $(P<0.01)$ (Table 2$)$.

The decidua of early pregnancy (gestational age $5-10$ weeks) exhibited similar activities of PG-, catecholamine- and forskolinstimulated adenylyl cyclase as those in the late proliferative phase, and no significant differences were seen between these two conditions. PG-stimulated adenylyl cyclase activity in late pregnancy (gestational age $37-40$ weeks) was significantly lower $(P<0.01)$ than that in early pregnancy (Fig. $5 a, b)$. There was a significant decrease in catecholamine- (Fig. $5 \mathrm{e}, \mathrm{f}$ ) and forskolin-stimulated (Fig. 5c) activities in the decidua of late pregnancy compared with those of early pregnancy $(P<0.05)$.

\section{Discussion}

The importance of cAMP in the regulation of cellular function has been clearly established in numerous tissues. However, the role of cAMP in the endometrium is not known. It is known that there are alterations in the cAMP content in the human endometrium during the menstrual cycle, and that cAMP concentrations are higher during the secretory phase than in the 
Table 1. Stimulation of adenylyl cyclase activities by catecholamines, prostaglandins and forskolin in the endometrium, myometrium, corpus luteum and Fallopian tube from the late secretory phase of the human menstrual cycle

\begin{tabular}{|c|c|c|c|c|c|c|c|}
\hline \multirow[b]{2}{*}{ Tissue } & \multirow[b]{2}{*}{$n$} & \multirow[b]{2}{*}{$\begin{array}{c}\text { Basal } \\
\text { activity }^{\mathrm{a}}\end{array}$} & \multicolumn{5}{|c|}{ Stimulated activity ${ }^{a}$} \\
\hline & & & $\begin{array}{l}\text { Isoproterenol } \\
\left.(30 \mu \mathrm{mol} \mathrm{l})^{-1}\right)\end{array}$ & $\begin{array}{l}\text { Adrenaline } \\
\left(30 \mu \mathrm{mol} \mathrm{l}^{-1}\right)\end{array}$ & $\begin{array}{c}\mathrm{PGE}_{2} \\
\left(30 \mu \mathrm{mol} \mathrm{l}^{-1}\right)\end{array}$ & $\begin{array}{c}\mathrm{PGF}_{2 a} \\
\left(30 \mu \mathrm{mol} \mathrm{l}^{-1}\right)\end{array}$ & $\begin{array}{c}\text { Forskolin } \\
\left(100 \mu \mathrm{mol} \mathrm{l}^{-1}\right)\end{array}$ \\
\hline Endometrium & 13 & $2.68 \pm 0.28$ & $3.28 \pm 0.41$ & $3.44 \pm 0.52$ & $7.03 \pm 0.90$ & $4.75 \pm 0.50$ & $31.2 \pm 2.6$ \\
\hline Myometrium & 4 & $0.59 \pm 0.14$ & $2.73 \pm 0.36$ & $2.75 \pm 0.30$ & $2.70 \pm 0.18$ & $1.79 \pm 0.88$ & $6.5 \pm 0.9$ \\
\hline Corpus luteum & 4 & $1.50 \pm 0.35$ & $1.99 \pm 0.24$ & $1.62 \pm 0.48$ & $1.23 \pm 0.32$ & $1.08 \pm 0.48$ & $18.1 \pm 0.7$ \\
\hline Fallopian tube & 4 & $2.12 \pm 0.56$ & $3.48 \pm 0.21$ & $3.78 \pm 0.26$ & $2.30 \pm 0.51$ & $1.31 \pm 0.46$ & $15.8 \pm 0.9$ \\
\hline
\end{tabular}

'Adenylyl cyclase activity is expressed as pmol cAMP formed $\mathrm{mg}$ ' protein min'-1.

Data represent means \pm SEM of quadruplicate measurements.

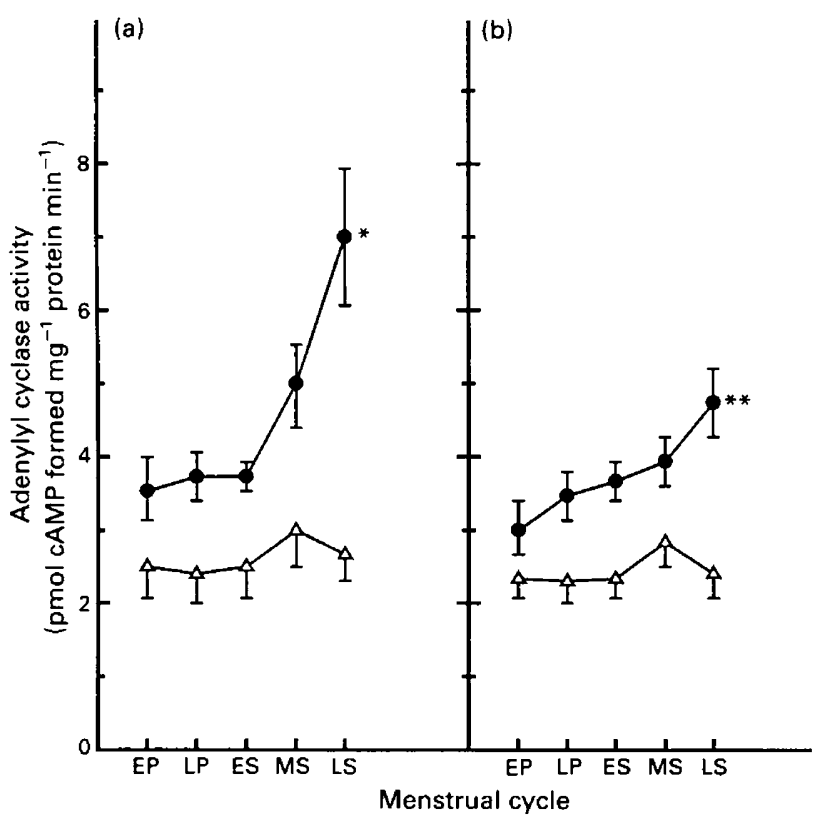

Fig. 2. Stimulation of adenylyl cyclase activity by (a) prostaglandin $E_{2}$ $\left(30 \mu \mathrm{mol} \mathrm{l}^{-1}\right)$ and (b) prostaglandin $\mathrm{F}_{2 \alpha}\left(30 \mu \mathrm{mol} \mathrm{l} \mathrm{l}^{-1}\right)$ in human endometrium during the menstrual cycle. Endometrial tissues were obtained during the menstrual cycle, and classified into five groups: EP: early proliferative; LP: late proliferative; ES: early secretory; MS: midsecretory and LS: late secretory phases. Data obtained in the absence $(\triangle)$ or presence $(-)$ of prostaglandin. Quadruplicate assays of adenylyl cyclase activity were performed for each value determined. Data represent means \pm SEM of the results obtained from 10-14 different endometria. "Significantly higher $(P<0.05)$ than the early proliferative (EP), late proliferative (LP) and early secretory (ES) phases. ${ }^{* *} \mathrm{Sig}$ nificantly higher $(P<0.05)$ than the early proliferative (EP) phase.

proliferative phase (Bergamini et al., 1985). Vilar-Rojas et al. (1982) reported that in rats endometrial cAMP concentrations and $\mathrm{CGMP}$ concentrations were higher at the implantation site than at other sites. Kennedy (1983) demonstrated that cholera toxin, an activator of adenylyl cyclase activity, markedly increased endometrial vascular permeability and induced decidualization in rats. Fleming et al. (1983) reported that cAMP reduces specific oestradiol binding and counteracts the effect of cGMP. These data suggest that cAMP plays an important

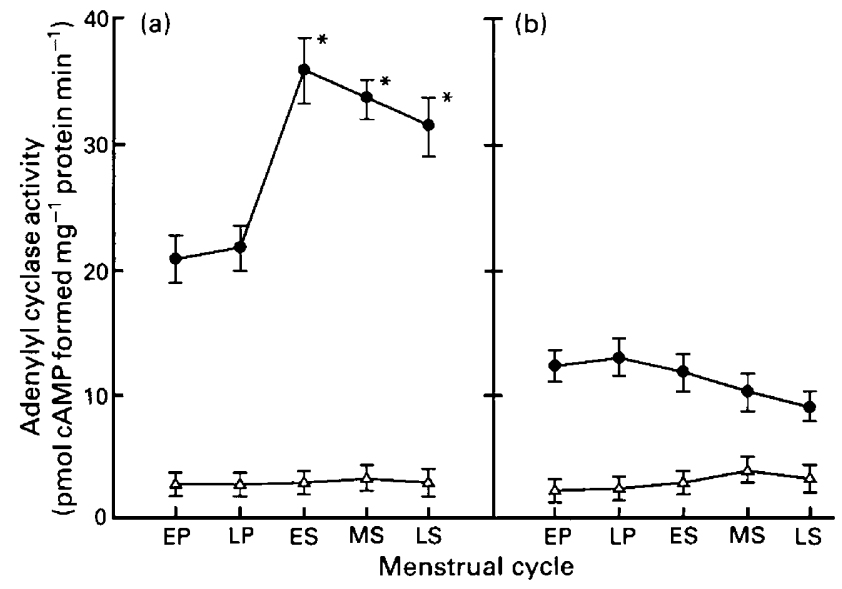

Fig. 3. Stimulation of adenylyl cyclase activity by (a) forskolin $\left(100 \mu \mathrm{mol} \mathrm{l}^{-1}\right)$ and (b) $\mathrm{NaF}\left(10 \mathrm{mmol} \mathrm{l}^{-1}\right)$ in human endometrium during the menstrual cycle. Endometrial tissues were obtained during the menstrual cycle, and classified into five groups: early proliferative (EP); late proliferative (LP); early secretory (ES); mid-secretory (MS) and late secretory (LS) phase. Data obtained in the absence $(\triangle)$ or presence (O) of forskolin or NaF. Quadruplicate assays of adenylyl cyclase activity were performed for each value determined. Data represent means \pm SEM of the results obtained from 10-18 different endometria. ${ }^{*}$ Significantly higher $(P<0.01)$ than the early proliferative (EP) phase.

physiological role in the endometrium, in the decidual reaction, in implantation and in nutrition of the blastocyst.

Significant quantities of PGs and catecholamines, stimulators of adenylyl cyclase activity, are present and cause alterations in the human uterus during the menstrual cycle. There is a significant increase in the concentration of $\mathrm{PGF}_{2 \alpha}$ in the endometrium during the secretory phase, with maximum concentrations of $\mathrm{PGF}_{2 \alpha}$ and $\mathrm{PGE}_{2}$ occurring at the onset of menstruation (Singh et al., 1975). The adrenaline concentration in the whole uterus, however, is high during the proliferative phase (Dujovne et al., 1976). Our data indicate that PG-stimulated adenylyl cyclase activity was high during the late secretory phase, and that catecholamine-stimulated activity was high during the proliferative and early secretory phases. The specific changes in PG- and catecholamine-stimulated adenylyl cyclase activity appear to coincide with changes in tissue content. This suggests that 


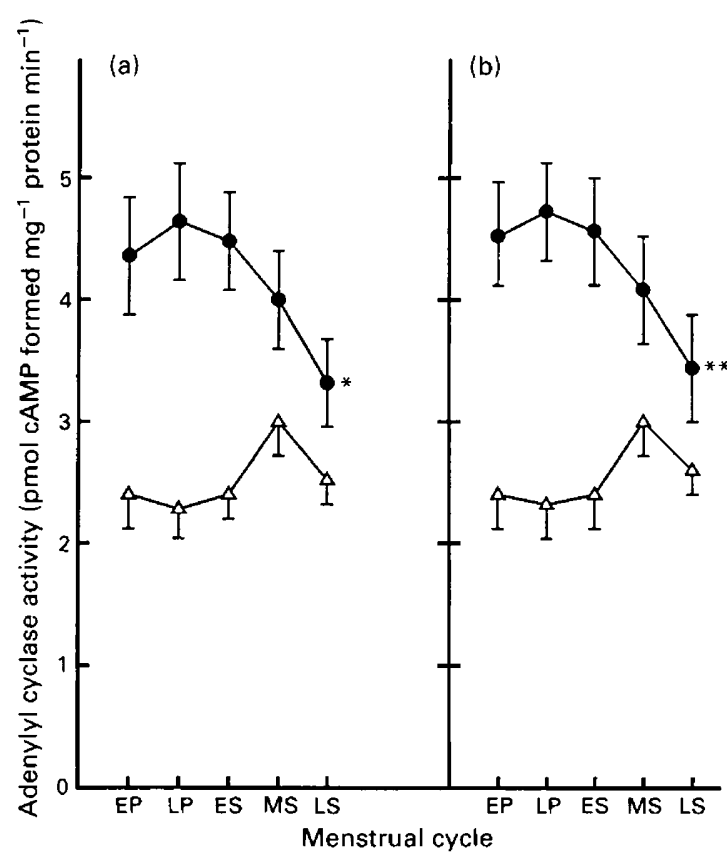

Fig. 4. Stimulation of adenylyl cyclase activity by (a) L-isoproterenol $\left(30 \mu \mathrm{mol} \mathrm{l}^{-1}\right)$ and (b) L-adrenaline $\left(30 \mu \mathrm{mol} \mathrm{l}^{-1}\right)$ in human endometrium during the human menstrual cycle. Endometrial tissues were obtained during the menstrual cycle, and classified into five groups, early proliferative (EP); late proliferative (LP); early secretory (ES); midsecretory (MS) and late secretory (LS) phase. Adenylyl cyclase activity was determined in the absence $(\triangle)$ or presence $(O)$ of catecholamine. Quadruplicate assays of adenylyl cyclase activity were performed for each value determined. Data represent means \pm SEM of the results obtained from 10-14 different endometria. ${ }^{*}$ Significantly lower $(P<0.01)$ than the late proliferative (LP) and early secretory (ES) phases. ${ }^{*}$ Significantly lower $(P<0.05)$ than the late proliferative (LP) phase.

Table 2. $\mathrm{EC}_{50}$ values for catecholamines, prostaglandins and forskolin during the most sensitive and insensitive phases of the human menstrual cycle

\begin{tabular}{lllc}
\hline Stimulant & Menstrual cycle & $n$ & $\begin{array}{c}\mathrm{EC}_{50}{ }^{\mathrm{a}} \\
\left(\mu \mathrm{mol} \mathrm{I}^{-1}\right)\end{array}$ \\
\hline \multirow{2}{*}{ Isoproterenol } & Late proliferative & 3 & $6.2 \pm 1.8$ \\
& Late secretory & 3 & $5.8 \pm 2.1$ \\
Adrenaline & Late proliferative & 3 & $6.4 \pm 2.6$ \\
& Late secretory & 3 & $5.1 \pm 1.1$ \\
Prostaglandin $\mathrm{E}_{2}$ & Late proliferative & 4 & $0.30 \pm 0.10$ \\
& Late secretory & 4 & $0.19 \pm 0.02$ \\
Prostaglandin $\mathrm{F}_{2 \alpha}$ & Late proliferative & 4 & $2.1 \pm 1.0$ \\
& Late secretory & 4 & $4.3 \pm 2.1$ \\
Forskolin & Early proliferative & 6 & $25.1 \pm 0.8$ \\
& Early secretory & 5 & $13.1 \pm 2.0^{*}$
\end{tabular}

${ }^{2}$ The $\mathrm{EC}_{50}$ values indicate the concentration giving the half maximal response. Values are expressed as means \pm SEM.

${ }^{*} p<0.01$ versus the early proliferative phase. endometrial cells can respond to PGs and catecholamines by increasing cAMP production, and that increased tissue content of cAMP and the response of adenylyl cyclase to PGs and catecholamines cooperatively plays some physiological role in the endometrium.

PGs may play an important role in the decidual process. Hoffman et al. (1977) showed that PGs, particularly of the E series, increased endometrial vascular permeability and subsequent decidualization, in rabbits.

The role of catecholamines in the regulation of glycogenolysis has been clearly established in numerous tissues. Human endometrial tissue is rich in glycogen, which might be an important energy source during implantation and in subsequent nutrition of the blastocyst. Souda et al. (1985) reported that there are changes in the activities of glycogen synthetase and glycogen phosphorylase during the menstrual cycle. However, the involvement of catecholamines in glycogenolysis in the endometrium has not been clearly established.

It is known that the endometrium consists primarily of two different cellular components - gland and stroma. PGs are synthesized mainly in the endometrial glands (Lumsden et al., 1984). Fortier et al. $(1987,1990)$ reported that $\mathrm{PGE}_{2}$-stimulated adenylyl cyclase activity was preferentially localized in stroma and is high during pregnancy, and that the presence of an embryo is associated with a local change in adenylyl cyclase activity in rabbit endometrium. Oestrogen-dependent adenylyl cyclase was shown by a cytochemical technique to be localized in the apical plasma membrane of endometrial glands but not in the endometrial stroma (Sananes and Psychoyos, 1974).

It is generally accepted that adenylyl cyclase is composed of three components: receptor, nucleotide regulatory protein and catalytic unit. Although the precise mechanisms remain to be elucidated, it has been proposed that catecholamines, and also PGs, activate adenylyl cyclase by binding to a plasma membrane receptor, while $\mathrm{NaF}$ interacts with the nucleotide regulatory protein and forskolin directly activates the catalytic unit (Miyazaki et al., 1984). Forskolin-stimulated adenylyl cyclase activity increased soon after ovulation, and reached its highest value in the early secretory phase. The $E_{50}$ values of forskolin-stimulated activity showed significant differences during the menstrual cycle. The maximum response and the sensitivity of enzyme were affected by forskolin. However, only the magnitude of adenylyl cyclase reponse was affected by PGs and catecholamines. Furthermore, PG- and catecholaminestimulated adenylyl cyclase activities reached peaks at different phases during the menstrual cycle. These findings suggest that the catalytic unit of adenylyl cyclase is regulated in a different manner from the plasma membrane receptor and the nucleotide regulatory protein, and that the regulatory mechanisms of nucleotide regulatory protein and plasma membrane receptors for PGs are completely different from those for catecholamines. Ovarian steroids may regulate the components of adenylyl cyclase, such as receptor, nucleotide regulatory protein and catalytic unit, via de novo synthesis and may control PG- and catecholamine-mediated cAMP production in human endometrium during the menstrual cycle and in human decidua during pregnancy.

Isoproterenol- and adrenaline-stimulated activities in the Fallopian tube were higher than in the endometrium, myometrium or corpus luteum. The smooth muscle of the Fallopian 


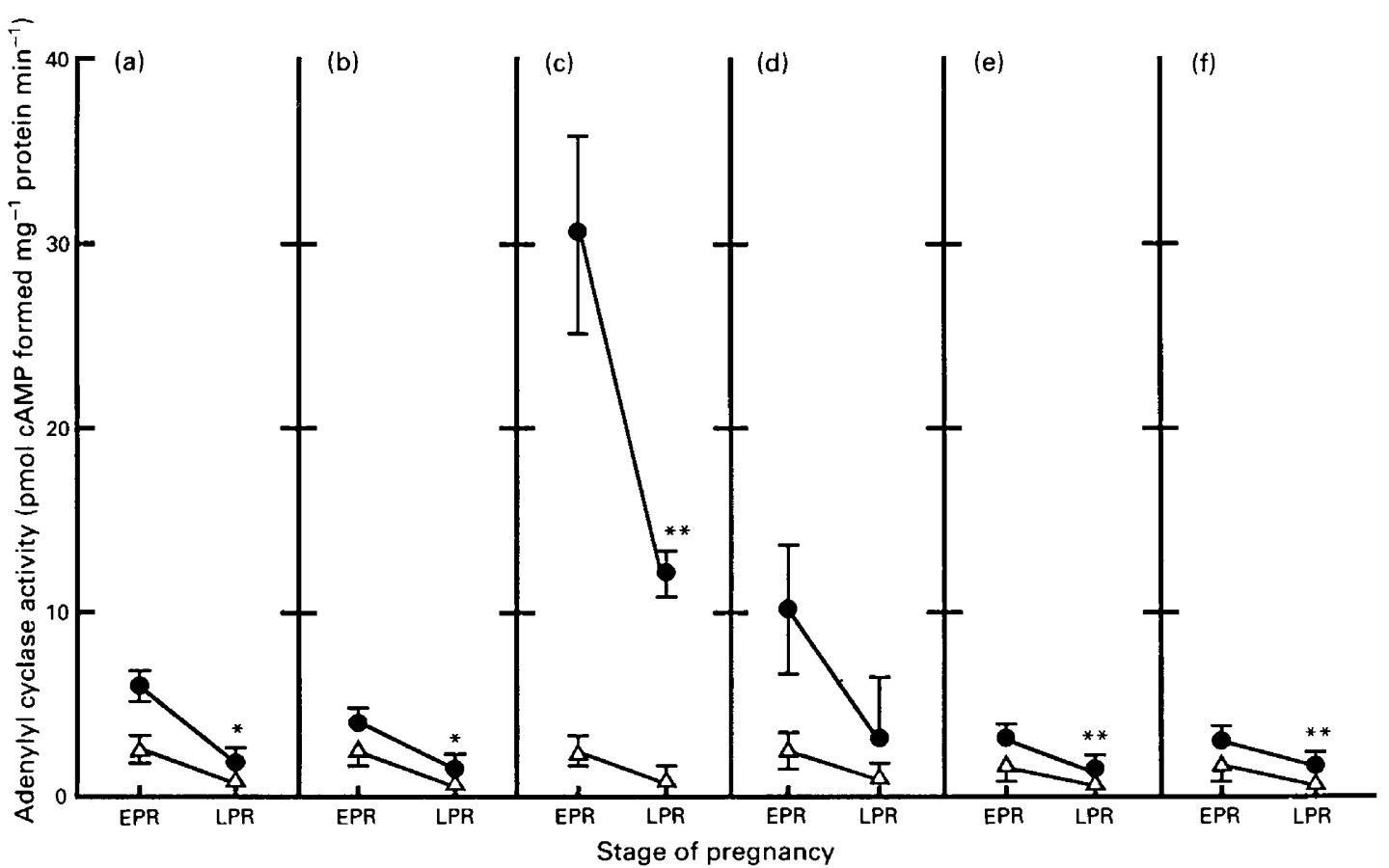

Fig. 5. Stimulation of adenylyl cyclase activity by (a) prostaglandin $E_{2}\left(30 \mu \mathrm{mol} \mathrm{l}^{-1}\right)$, (b) prostaglandin $\mathrm{F}_{2 \alpha}\left(30 \mu \mathrm{mol} \mathrm{l}^{-1}\right)$, (c) forskolin $\left(100 \mu \mathrm{mol} \mathrm{l}^{-1}\right)$, (d) $\mathrm{NaF}\left(10 \mathrm{mmol} \mathrm{l}^{-1}\right)$, (e) L-isoproterenol $\left(30 \mu \mathrm{mol} \mathrm{l}^{-1}\right)$ and (f) L-adrenaline $\left(30 \mu \mathrm{mol} \mathrm{l}^{-1}\right)$ in human decidua during pregnancy. Decidual tissues were obtained in early pregnancy (EPR) at gestational ages 5-10 weeks and late pregnancy (LPR) at gestational ages 37-40 weeks. Adenylyl cyclase activity was determined in absence $(\triangle)$ or presence $(O)$ of stimulants. Quadruplicate assays of adenylyl cyclase activity were performed for each value determined. Data represent means \pm SEM of the results obtained from five different decidua in early pregnancy and five different decidua in late pregnancy. ${ }^{*}$ Significantly lower $(P<0.01)$ than early pregnancy (EPR). ${ }^{*}$ Significantly lower $(P<0.05)$ than early pregnancy $(\mathrm{EPR})$.

tube is innervated by adrenergic nerve fibres along its entire length (Brundin and Wirsen, 1964). Alpha- and beta-adrenergic receptors mediating changes in resting pressure (Rosenblum and Stein, 1966) and motility (Nakanishi et al., 1967) have been demonstrated in human Fallopian tubes in vivo and in vitro. These results indicate that the neurotransmitter may directly activate the adenylyl cyclase in the Fallopian tube, and play an important role in transport of the fertilized ovum.

In summary, we demonstrated that specific changes in adenylyl cyclase activity occur in human endometria during the menstrual cycle and in human decidua during pregnancy. These results suggest that changes in adenylyl cyclase activity in the endometrium and decidua are regulated by ovarian steroid hormones. PG- and catecholamine-stimulated adenylyl cyclase may play an important role in the implantation of the human blastocyst and in the regulation of human decidual functions. Further studies will be needed to clarify the precise mechanisms and physiological roles of these endometrial and decidual changes in adenylyl cyclase activity.

\section{References}

Bekairi AM, Sanders RB, Abulaban FS and Yochim JM (1984) Role of ovarian steroid hormones in the regulation of adenylate cyclase during early progestation Biology of Reproduction 31 742-751

Bergamini CM, Pansini F, Bettocchi S Jr, Segala V, Dallocchio F, Bagni B and Mollica G (1985) Hormonal sensitivity of adenylate cyclase from human endometrium: modulation by estradiol Journal of Steroid Biochemistry 22 299-303

Bhalla RC, Sanborn BM and Korenman SG (1972) Hormonal interactions in the uterus: inhibition of isoproterenol-induced accumulation of adenosine $3^{\prime}: 5^{\prime}$ cyclic monophosphate by oxytocin and prostaglandins Proceedings of the National Academy of Sciences USA 69 3761-3764

Brown BL, Albano JDM, Ekins RP and Sgherzi AM (1971) A simple and sensitive saturation assay method for the measurement of adenosine $3^{\prime}, 5^{\prime}$-cyclic monophosphate Biochemical Journal 121 561-562

Brundin J and Wirsen C (1964) Adrenergic nerve terminals in the human Fallopian tube examined by fluorescence microscopy Acta Physiologica Scandinavica 61 505-506

Costa MRC, Casnellie JE and Catterall WA (1982) Selective phosphorylation of the $\alpha$-subunit of the sodium channel by cAMP-dependent protein kinase Journal of Biological Chemistry 257 7918-7921

Dujovne AR, De Laborde NP, Carril LM, Cheviakoff S, Pedroza E and Rosner JM (1976) Correlation between catecholamine content of the human Fallopian tube and the uterus and plasma levels of estradiol and progesterone American Journal of Obstetrics and Gynecology 124 229-233

Fleming H, Blumenthal R and Gurpide E (1983) Rapid changes in specific estrogen binding elicited by cGMP or cAMP in cytosol from human endometrial cells Proceedings of the National Academy of Sciences USA $\mathbf{8 0}$ 2486-2490

Fortier MA, Boulanger AP, Boulet AP and Lambert RD (1987) Cell-specific localization of prostaglandin $E_{2}$-sensitive adenylate cyclase in rabbit endometrium Biology of Reproduction 36 1025-1033

Fortier MA, Boulet AP, Dugre FJ and Lambert RD (1990) Local alteration in adenylate cyclase activity and stimulation response at implantation site in rabbit endometrium during early pregnancy Biology of Reproduction 42 106-113

Hoffman LH, Strong GB, Davenport GR and Frolich JC (1977) Deciduogenic effect of prostaglandins in the pseudopregnant rabbit Joumal of Reproduction and Fertility 50 231-237 
Houserman VL, Todd H and Hertelendy F (1989) Progesterone treatment in vitro enhances prostaglandin $\mathrm{E}$ and forskolin-promoted cyclic AMP production in human endometrial stromal cells Journal of Reproduction and Fertility $\mathbf{8 5}$ 195-202

Karim SMM, Trussell RR, Patel RC and Hillier K (1968) Response of pregnant human uterus to prostaglandin- $\mathrm{F}_{2 \mathrm{a}}$-induction of labour British Medical joumal $4621-623$

Kennedy TG (1983) Prostaglandin $E_{2^{\prime}}$ adenosine $3^{\prime}: 5^{\prime}$-cyclic monophosphate and changes in endometrial vascular permeability in rat uteri sensitized for the decidual cell reaction Biology of Reproduction 29 1069-1076

Lowry OH, Rosebrough NJ, Farr AL and Randall RJ (1951) Protein measurement with the Folin phenol reagent Journal of Biological Chemistry 193 265-276

Lumsden MA, Brown A and Baird DT (1984) Prostaglandin production from homogenates of separated glandular epithelium and stroma from human endometrium Prostaglandins 28 485-496

Miyazaki K, Miyamoto E, Maeyama M and Uchida M (1980a) Specific regulation by steroid hormones of protein kinases in the endometrium 1 . Alteration by estrogen and progesterone in levels of protein kinases in rabbit endometrium European Journal of Biochemistry 104 535-542

Miyazaki K, Miyamoto E, Maeyama M and Uchida M (1980b) Specific regulation by steroid hormones of protein kinases in the endometrium. 2. Alteration in levels of protein kinases in human endometrium during the menstrual cycle European Journal of Biochemistry 104 543-547

Miyazaki K, Goldman ME and Kebabian JW (1984) Forskolin stimulates adenylate cyclase activity, adenosine $3^{\prime}, 5^{\prime}$-monophosphate production and peptide release from the intermediate lobe of the rat pituitary gland Endocrinology 114 761-766

Nakanishi H, Wansbrough H and Wood C (1967) Postganglionic sympathetic nerve innervating human fallopian tube American Journal of Physiology 213 613-619

Noyes RW, Hertig AT and Rock J (1950) Dating the endometrial biopsy Fertility and Sterility 1 3-25

Owman CH, Sjoberg N-O, Svennson K-G and Walles B (1975) Autonomic nerves mediating contractility in the human Graafian follicle journal of Reproduction and Fertility 45 553-556
Powell WS, Hammarstrom KM, Samuelsson B and Sjoberg B (1974) Prostaglandin F $2 \alpha$ receptor in human corpora lutea Lancet 11120

Reuter H (1983) Calcium channel modulation by neurotransmitters, enzymes and drugs Nature 301 569-575

Rosenblum I and Stein AA (1966) Autonomic response of the circular muscles of the isolated human Fallopian tube American Journal of Physiology 210 $1127-1129$

Sananes N and Psychoyos A (1974) Cytochemical localization of adenyl cyclase in the rat uterus Journal of Reproduction and Fertility 38 181-183

Singh EJ, Baccarini IM and Zupan FP (1975) Levels of prostaglandins $\mathrm{F}_{2 \alpha}$ and $\mathrm{E}_{2}$ in human endometrium during the menstrual cycle American Joumal of Obstetrics and Gynecology 121 1003-1006

Souda Y, Fukuma K, Kawano T, Tanaka T, Matsuo I and Maeyama M (1985) Activities of glycogen synthetase and glycogen phosphorylase in the human endometrium: relative distribution in isolated glands and stroma American Joumal of Obstetrics and Gynecology 153 100-105

Spilman CH (1974) Oviduct motility in the rhesus monkey: spontaneous activity and response to prostaglandins Fertility and Sterility 25 935-939

Stefenson A, Owman C, Sjoberg N-O, Sporrong B and Walles B (1981) Comparative study of the autonomic innervation of the mammalian ovary, with particular regard to the follicular system Cell and Tissue Research 215 47-62

Vesin M-F, Khac LD and Harbon S (1978) Modulation of intra-cellular adenosine cyclic $3^{\prime}, 5^{\prime}$-monophosphate and contractility of rat uterus by prostaglandins and polysaturated fatty acid Molecular Pharmacology 14 24-37

Vilar-Rojas C, Castro-Osuna G and Hicks JJ (1982) Cyclic AMP and cyclic GMP in the implantation site of the rat International Journal of Fertility $2756-59$

Weiss GK, Dail WG and Ratner A (1982) Evidence for direct neural control of ovarian steroidogenesis in rats Joumal of Reproduction and Fertility 65 507-511

Wheeler AG, Walker M and Lean J (1987) Influence of adrenergic receptors on ovarian progesterone secretion in the pseudopregnant cat and oestradiol secretion in the oestrous cat Joumal of Reproduction and Fertility 79 195-205

Whitsett JA and Johnson C (1979) Adenylate cyclase from human decidua parietalis American Joumal of Obstetrics and Gynecology 133 479-483 